\title{
Worsening of Acute Cholangitis Caused by a Bile Duct Stone After Hospitalization: A Case Series
}

\author{
Tetsuro Akashia, b, Yuichi Tachibana ${ }^{\mathrm{a}}$, Susumu Matsuo ${ }^{\mathrm{a}}$, \\ Junya Gibo ${ }^{a}$
}

\begin{abstract}
Acute cholangitis is a fatal condition if inadequately treated. It is possible to underestimate the severity of the condition because bacterial cultures are not immediately available. We evaluated the clinical features of patients with cholangitis due to bile duct stones who were diagnosed with severe bacteremia at the time of hospitalization, but not at the time of the initial visit. We conducted a retrospective analysis of cases of endoscopic retrograde cholangiopancreatography performed between January 2007 and October 2011 in patients with bile duct stones complicated by cholangitis. The severity of cholangitis was assessed based on the 2005 Japanese Evidence-Based Practice Guidelines for the Management of Acute Cholangitis and Cholecystitis (JG05). Of 130 cases, 23 were diagnosed as severe cholangitis, including 11 of bacterial cause. However, based on the JG05, two cases were classified as "mild" at initial assessment and nine cases as "moderate". A history of endoscopic sphincterotomy (EST) was identified in the two cases classified as "mild" cholangitis. Obstruction by a bile duct stone, possibly due to reflux from the duodenum, can lead to rapid progression to sepsis in a short time. For patients with a history of EST, early biliary drainage is necessary to prevent rapid progression of bacterial cholangitis.
\end{abstract}

Keywords: Cholangitis; Bile duct stone; Bacteremia; Endoscopic biliary drainage; Patient acuity

\section{Introduction}

Acute cholangitis can be fatal if not treated adequately. A rapid onset of symptoms of cholangitis caused by bile duct stones is particularly concerning and requires immediate diagnosis and treatment, which can be facilitated by the emergent use of endoscopy for early identification of serious cases of cholangitis.

Manuscript submitted October 28, 2017, accepted November 15, 2017

${ }^{a}$ Department of Internal Medicine, Saiseikai Fukuoka General Hospital, Fukuoka, Japan

${ }^{b}$ Corresponding Author: Tetsuro Akashi, Department of Internal Medicine, Saiseikai Fukuoka General Hospital, 1-3-46 Tenjin, Chuo-ku, Fukuoka 8100001, Japan. Email: tetsu71jpjp@yahoo.co.jp

doi: https://doi.org/10.14740/gr930w
However, no evidence-based practice guidelines were available before 2003 to determine patient diagnosis and disease severity [1]. The Evidence-Based Practice Guidelines for the Management of Acute Cholangitis and Cholecystitis (JG05) were published in Japanese in 2005 [2]. Following an international consensus meeting in 2005, the Tokyo Guidelines 2007 (TG07) for patients with acute cholangitis [3, 4] was the first set of international guidelines that specifically addresses the problem of diagnosis and severity of acute cholangitis [5, 6]. Although the 2005 and 2007 guidelines are of merit, there was a need to merge their recommendations. Therefore, the updated Tokyo Guidelines 2013 (TG13) was compiled as a revision of the JG05 and addressed the limitations of the TG07 $[7,8]$. The TG13 is synonymous with the Japanese version of the 2013 Clinical Practice Guidelines (JG13) [9].

Based on these guidelines, bacteremia is a cause of sudden deterioration in health status, with early biliary drainage considered to be necessary [10]. However, due to the need for culture results, the severity of bacteremia is not always immediately known, which leads to the possibility that disease severity may be underestimated at the time of hospitalization. This inherently became one of the limitations of the JG05 severity grading system. To address this limitation, the JG13 modified the description of the criteria for "severity" to include dysfunction of at least one of the six principal organ systems, namely cardiovascular, nervous, respiratory, kidney, liver, and blood function. According to these revisions, it is possible that cases of "severe" bacteremia requiring immediate biliary drainage according to the JG05 may not be considered "severe" according to the JG13 guidelines. Therefore, we sought to retrospectively evaluate the clinical features of patients with cholangitis due to bile duct stones who were diagnosed with severe bacteremia at the time of hospitalization, but not at the time of the initial admission. The ethics committee of Saiseikai Fukuoka General Hospital (No. 2016-2-1, February 19, 2016) approved this study and waived the requirement for informed consent.

\section{Case Reports}

Between January 2007 and October 2011, we performed 227 cases of endoscopic retrograde cholangiopancreatography (ERCP) in patients with bile duct stones. Among these cases, 130 were complicated with cholangitis. The mean age (range) of patients with cholangitis was 75.2 (43 - 98) years, including 
Table 1. Clinical Features of Severe Cholangitis $(n=11)$ With Bacteremia Diagnosed After Admission

\begin{tabular}{|c|c|c|c|c|c|c|}
\hline Case no. & Age/sex & Time to biliary drainage* & Severity of JG05 & Severity of JG13 & $\begin{array}{l}\text { History of endoscopic } \\
\text { treatment of cholangitis }\end{array}$ & Outcome \\
\hline 1 & $82 / \mathrm{M}$ & Within $5 \mathrm{~h}$ & Moderate & Severe & None & Alive \\
\hline 3 & $77 / \mathrm{M}$ & 5 to $24 \mathrm{~h}$ & Mild & Mild & EST & Dead \\
\hline 4 & $71 / \mathrm{M}$ & 5 to $24 \mathrm{~h}$ & Moderate & Moderate & None & Alive \\
\hline 7 & $78 / \mathrm{F}$ & Within $5 \mathrm{~h}$ & Mild & Mild & EST & Alive \\
\hline 8 & $84 / \mathrm{M}$ & Within $5 \mathrm{~h}$ & Moderate & Mild & None & Alive \\
\hline 9 & $72 / \mathrm{M}$ & 5 to $24 \mathrm{~h}$ & Moderate & Severe & None & Alive \\
\hline 10 & $69 / \mathrm{M}$ & Within $5 \mathrm{~h}$ & Moderate & Severe & EST & Alive \\
\hline
\end{tabular}

*Time from first visit to the start of endoscopic biliary drainage. JG05: 2005 Japanese Evidence-Based Clinical Practice Guidelines for the Management of Acute Cholangitis and Cholecystitis; JG13: revised edition of the JG05 published in 2013; EST: endoscopic sphincterotomy; M: male; F: female. Age is reported in years.

79 men and 51 women. Of these patients, 74 (56.9\%) sought consultation during regular clinic hours on weekdays and 56 (43.1\%) during holidays or evening hours. The outcome of acute cholangitis improved in $98.5 \%$ of cases (128/130); two cases where the patients died were classified as severe cholangitis. Taking into consideration the time period of the study (2007 - 2011), the severity of acute cholangitis was determined based on the JG05 guidelines. "Severe" cholangitis was defined based on one or more of the following: physiological shock, bacteremia, impaired consciousness, and acute renal failure. The criteria for "moderate" severity of acute cholangitis included any one of the following: jaundice (bilirubin $>2.0 \mathrm{mg} / \mathrm{dL}$ ), hypoalbuminemia (albumin $<3.0 \mathrm{~g} / \mathrm{dL}$ ), renal dysfunction (creatinine $>1.5 \mathrm{mg} / \mathrm{dL}$, blood urea nitrogen $>20$ $\mathrm{mg} / \mathrm{dL})$, low platelet count $\left(<120,000 / \mathrm{mm}^{3}\right)$, and fever $(>39$ $\left.{ }^{\circ} \mathrm{C}\right)$. Cases that did not meet the criteria for "severe" or "moderate" cholangitis were considered "mild" cases. According to the JG05 guidelines, of 130 cases, $23(17.7 \%)$ were severe, 82 $(63.1 \%)$ were moderate, and $25(19.2 \%)$ were mild. Among the 23 cases of severe cholangitis, 11 were due to bacteremia (Table 1), of which two cases were classified as "mild" based on the JG05 at the first visit and nine as "moderate". Alternatively, when using the JG13 criteria, four cases were "severe", three were "moderate", and four were "mild". The time to ERCP and biliary drainage was within $5 \mathrm{~h}$ in six cases and within $24 \mathrm{~h}$ in the remaining five cases. A history of endoscopic sphincterotomy (EST) was identified in three of the 11 cases of "severe" cholangitis. Two cases classified as "mild" cholangitis according to the JG05 were also classified as "mild" on the JG13 after EST, with one of these cases progressing to death. Both cases are presented in detail as below.

\section{Case 1}

A 78-year-old woman sought consultation for upper abdomi- nal pain. She had undergone EST and laparoscopic cholecystectomy 7 years before the consultation. Abdominal computed tomography (CT) revealed two stones in the lower portion of the common bile duct, one with a 1-cm diameter and the other with a $2.4-\mathrm{cm}$ diameter. The patient was conscious and her vital signs were as follows: body temperature, $35.8^{\circ} \mathrm{C}$; blood pressure, 158/69 $\mathrm{mm} \mathrm{Hg}$; pulse rate, 98 beats/min. The laboratory data revealed signs of mild inflammation and elevation in hepatobiliary enzymes. Based on the clinical and laboratory findings, a diagnosis of mild acute cholangitis was made (Table 2). Antibiotic treatment was initiated within $5 \mathrm{~h}$ of admission, followed by EST and endoscopic lithotripsy. Blood pressure temporarily decreased in the evening of the first day and subsequently improved with dopamine hydrochloride treatment. The postoperative course was uneventful, and the patient was discharged on post-admission day 6. Klebsiella pneumoniae was confirmed from blood cultures performed at admission.

\section{Case 2}

A 77-year-old man presented to our institution in the evening with upper abdominal pain. He had undergone open cholecystectomy 25 years prior and EST 3 years prior. CT imaging revealed two stones in the common bile duct, one with a diameter of $0.8 \mathrm{~cm}$ and the other $0.7 \mathrm{~cm}$. The patient was conscious with the following vital signs: body temperature, 36.1 ${ }^{\circ} \mathrm{C}$; blood pressure, 167/66 mm Hg; pulse rate, 75 beats/min. Laboratory tests revealed signs of mild inflammation and elevated hepatobiliary enzyme (Table 2). The patient was hospitalized with a diagnosis of mild acute cholangitis. The patient did not consent to biliary drainage on the day of admission. In the morning of the next day, the patient developed dyspnea, hypotension, and tachycardia, and emergent endoscopic biliary drainage was performed. The patient's condition did 
Table 2. Comparison of Laboratory Findings at the Initial Evaluation for Cases 1 and 2

\begin{tabular}{|c|c|c|}
\hline Variable & Case 1 & Case 2 \\
\hline \multicolumn{3}{|l|}{ Peripheral blood } \\
\hline $\mathrm{WBC}, / \mu \mathrm{L}$ & 8,600 & 14,000 \\
\hline $\mathrm{RBC}, / \mu \mathrm{L}$ & $427 \times 10^{4}$ & $454 \times 10^{4}$ \\
\hline $\mathrm{Hb}, \mathrm{g} / \mathrm{dL}$ & 12.5 & 14.3 \\
\hline $\mathrm{Ht}, \%$ & 39.3 & 42 \\
\hline $\mathrm{PLT}, / \mu \mathrm{L}$ & $21.5 \times 10^{4}$ & $18.7 \times 10^{4}$ \\
\hline \multicolumn{3}{|l|}{ Coagulation } \\
\hline PT, $\%$ & 95 & Not done \\
\hline \multicolumn{3}{|l|}{ Biochemistry } \\
\hline T-Bil, mg/dL & 1.1 & 1.6 \\
\hline AST, IU/L & 189 & 371 \\
\hline ALT, IU/L & 59 & 149 \\
\hline LDH, IU/L & 356 & 569 \\
\hline ALP, IU/L & 355 & 732 \\
\hline$\gamma$-GTP, IU/L & 198 & 412 \\
\hline $\mathrm{ALB}, \mathrm{g} / \mathrm{dL}$ & 3.8 & 4.4 \\
\hline $\mathrm{BUN}, \mathrm{mg} / \mathrm{dL}$ & 15 & 14 \\
\hline Cre, mg/dL & 0.5 & 0.6 \\
\hline AMY, IU/L & 112 & 125 \\
\hline $\mathrm{CRP}, \mathrm{mg} / \mathrm{dL}$ & 0.04 & 0.1 \\
\hline
\end{tabular}

WBC: white blood cell; RBC: red blood cell; Hb: hemoglobin; PLT: platelet; PT: prothrombin time; T-Bil: total bilirubin; AST: aspartate aminotransferase; ALT: alanine aminotransferase; LDH: lactate dehydrogenase; ALP: alkaline phosphatase; $\gamma$-GTP: $\gamma$-glutamyl transpeptidase; ALB: albumin; BUN: blood urea nitrogen; Cre: creatinine; AMY: amylase; CRP: C-reactive protein.

not improve with intensive care and he died on post-admission day 9. Escherichia coli was detected from blood cultures performed at admission.

\section{Discussion}

In our retrospective study, we observed that patients with acute cholangitis often sought urgent care after regular clinic hours. Prompt assessment of the severity of cholangitis, regardless of the time of consultation, and planning for emergent biliary drainage are necessary. In our case series, we identified two cases of cholangitis-related death. The first was a patient who went into physiological shock during transportation and could not be revived on arrival. However, the other patient was diagnosed with mild cholangitis at the initial visit, which progressed to septic shock within $12 \mathrm{~h}$ of admission. This motivated us to identify clinical features associated with bacterial acute cholangitis that were not assessed as severe cases at the time of admission.

The criteria for severity of cholangitis vary depending on the guidelines used. In our case series, nine patients were identified to have moderate cholangitis using JG05, whereas only three were considered to have moderate cholangitis using JG13. There was no difference between the JG05 and JG13 for the identification of mild cases of cholangitis. It should be noted that all cases classified as mild using JG05 involved patients with a previous history of EST. After EST, a high incidence (19-67\%) of pneumobilia, often associated with reflux from the duodenum to the bile duct, has previously been reported [11-13]. After EST, a positive bacterial culture was identified in $60-88 \%$ of the cases with bile reflux [13-15]. Based on this evidence, we consider that obstruction of the bile duct can rapidly progress to sepsis. Therefore, in patients with a history of EST, early biliary drainage should be implemented, even in cases initially assessed as mild cholangitis.

\section{Acknowledgments}

The authors thank Editage (www.editage.jp) for the English language review.

\section{Conflict of Interest}

The authors state that they have no conflict of interest.

\section{Financial Disclosures}

None.

\section{Grant Support}

This research received no grants from any funding agency.

\section{References}

1. Kiriyama S, Takada T, Strasberg SM, Solomkin JS, Mayumi T, Pitt HA, Gouma DJ, et al. New diagnostic criteria and severity assessment of acute cholangitis in revised Tokyo Guidelines. J Hepatobiliary Pancreat Sci. 2012;19(5):548-556.

2. Takada T, Nimura Y, Hirata K, Kawarada Y, Yasuda H, Yamashita Y, Kimura Y, et al. Evidence-based clinical practice guidelines for the management of acute cholangitis and cholecystitis. 1st ed. Tokyo: Igaku Tosho Shuppan. 2005.

3. Takada T, Kawarada Y, Nimura Y, Yoshida M, Mayumi T, Sekimoto M, Miura F, et al. Background: Tokyo Guidelines for the management of acute cholangitis and cholecystitis. J Hepatobiliary Pancreat Surg. 2007;14(1):1-10.

4. Wada K, Takada T, Kawarada Y, Nimura Y, Miura F, Yoshida M, Mayumi T, et al. Diagnostic criteria and severity assessment of acute cholangitis: Tokyo Guidelines. J Hepatobiliary Pancreat Surg. 2007;14(1):52-58.

5. Tsuyuguchi T, Sugiyama H, Sakai Y, Nishikawa T, Yoko- 
suka O, Mayumi T, Kiriyama S, et al. Prognostic factors of acute cholangitis in cases managed using the Tokyo Guidelines. J Hepatobiliary Pancreat Sci. 2012;19(5):557565.

6. Nishino T, Onizawa S, Hamano M, Shirato I, Shirato M, Hamano T, Tagata T, et al. Proposed new simple scoring system to identify indications for urgent ERCP in acute cholangitis based on the Tokyo Guidelines. J Hepatobiliary Pancreat Sci. 2012;19(6):698-706.

7. Kiriyama S, Takada T, Strasberg SM, Solomkin JS, Mayumi T, Pitt HA, Gouma DJ, et al. TG13 guidelines for diagnosis and severity grading of acute cholangitis (with videos). J Hepatobiliary Pancreat Sci. 2013;20(1):24-34.

8. Miura F, Takada T, Strasberg SM, Solomkin JS, Pitt HA, Gouma DJ, Garden OJ, et al. TG13 flowchart for the management of acute cholangitis and cholecystitis. J Hepatobiliary Pancreat Sci. 2013;20(1):47-54.

9. Mayumi T, Someya K, Ootubo H, Takama T, Kido T, Kamezaki F, Yoshida M, et al. Progression of Tokyo Guidelines and Japanese Guidelines for management of acute cholangitis and cholecystitis. J UOEH. 2013;35(4):249-257.

10. Lee F, Ohanian E, Rheem J, Laine L, Che K, Kim JJ. De- layed endoscopic retrograde cholangiopancreatography is associated with persistent organ failure in hospitalised patients with acute cholangitis. Aliment Pharmacol Ther. 2015;42(2):212-220.

11. Staritz M, Ewe K, Meyer zum Buschenfelde KH. Investigation of the sphincter of Oddi before, immediately after and six weeks after endoscopic papillotomy. Endoscopy. 1986;18(1):14-16.

12. Saito M, Tsuyuguchi T, Yamaguchi T, Ishihara T, Saisho H. Long-term outcome of endoscopic papillotomy for choledocholithiasis with cholecystolithiasis. Gastrointest Endosc. 2000;51(5):540-545.

13. Sugiyama M, Atomi Y. Does endoscopic sphincterotomy cause prolonged pancreatobiliary reflux? Am J Gastroenterol. 1999;94(3):795-798.

14. Gregg JA, De Girolami P, Carr-Locke DL. Effects of sphincteroplasty and endoscopic sphincterotomy on the bacteriologic characteristics of the common bile duct. Am J Surg. 1985;149(5):668-671.

15. Sand J, Airo I, Hiltunen KM, Mattila J, Nordback I. Changes in biliary bacteria after endoscopic cholangiography and sphincterotomy. Am Surg. 1992;58(5):324328. 